\title{
RANCANG BANGUN E- COMMERCE TOKO RAFFAMART PALEMBANG MENGGUNAKAN MACROMEDIA DREAMWEAVER
}

\author{
Muhammad Nasir ${ }^{1}$, Imam Solikin ${ }^{2}$ \\ 1,2 Dosen Universitas Bina Darma \\ Jalan Jenderal Ahmad Yani No.3 Palembang \\ Sur-el: nasir@binadarma.ac.id ${ }^{1}$, imamsolikin@binadarma.ac.id ${ }^{1}$
}

\begin{abstract}
Abstrak: Raffamart Store is one of the trading business that sells various clothes. This store has not provided product sales service via internet or e-commerce (Electronic Commerce). In the process of selling ordering products as well as transactions, customers must come directly to the store. Customers can not place product orders due to system limitations owned by Raffamart stores. Therefore, a web-based sales system (e-commerce) is needed to assist the store in promoting the product. System development method used is waterfall method. The tools used to illustrate the system model are use case diagrams, activity diagrams and class diagrams. This website was developed using macromedia dreamweaver, programming language PHP and $M y S Q L$ as database. With this web-based system, of course, will facilitate the processing of product data for sale and also help in terms of product marketing, because any information provided to customers can be faster.
\end{abstract}

Keywords: E-Commerce, Raffamart Store, Macromedia Dreamweaver, php, mysql, Website

\begin{abstract}
Toko Raffamart adalah salah satu bisnis yang bergerak dibidang perdagangan yang menjual berbagai macam pakaian. Dalam proses penjualan produk pemesanan serta transaksi, pelanggan harus datang langsung ke toko. Pelanggan tidak dapat melakukan pemesanan produk karena keterbatasan sistem yang dimiliki oleh toko Raffamart. Oleh karena itu, diperlukan sistem penjualan berbasis web (e-commerce) untuk membantu pihak toko dalam melakukan promosi produk. Metode pengembangan sistem yang digunkan adalah metode waterfall. Alat yang digunakan untuk menggambarkan model sistem adalah use case diagram, activity diagram dan class diagram. Website ini dikembangkan menggunakan macromedia dreamweaver, bahasa pemrograman PHP dan MySQL sebagai database. Dengan adanya sistem berbasis web ini, tentunya akan mempermudah pengolahan data produk untuk dijual dan juga membantu dalam hal pemasaran produk, karena setiap informasi yang diberikan kepada pelanggan bisa lebih cepat.
\end{abstract}

Kata Kunci: E-Commerce, Toko Raffamart, Macromedia Dreamweaver, php, mysql, Website

\section{PENDAHULUAN}

Perkembangan Teknologi Informasi di berbagai bidang kehidupan memberikan banyak kemudahan dalam menyelesaikan permasalahanpermasalahan di berbagai bidang. Salah satu produk teknologi informasi itu adalah internet, yang merupakan media informasi yang sangat penting untuk mengetahui atau mencari informasi yang dibutuhkan. Internet merupakan salah satu hasil dari kemajuan dan perkembangan teknologi yang paling populer saat ini. Internet sebagai produk Teknologi Informasi, saat sudah banyak digunakan untuk membantu transaksi penjualan dalam usaha memperluas jangkauan pemasaran produk yang dimiliki.

Penjualan sendiri memiliki arti yang cukup luas. Banyak penjelasan yang berkaitan dengan penjualan. Beberapa ahli menyebutnya Penjualan sebagai ilmu dan beberapa lainnya menyebutnya sebagai seni. Adapula yang 
memasukkan etik dalam penjualan. Secara umum, istilah menjual dapat diartikan sebagai ilmu dan seni mempengaruhi pribadi yang dilakukan oleh penjual untuk mengajak orang lain agar bersedia membeli produk/jasa yang ditawarkan. (Swastha, 2015). Jenis-jenis penjualan sendiri dapat dikelompokkan menjadi:1) Trade Selling, dapat terjadi apabila produsen dan pedagang besar mempersilakan pengecer untuk berusaha memperbaiki distributor barang-barang mereka. Hal ini melibatkan para penyalur dengan kegiatan promosi, peragaan, persediaan dan produk baru, 2) Missionary Selling, Penjualan berusaha ditingkatkan dengan mendorong pembeli untuk membeli barang-barang dari penyalur perusahaan, 3) Technical Selling, Berusaha meningkatkan penjualan dengan pemberian saran dan nasehat kepada pembeli akhir dari produk dan jasanya, 4) New Business Selling, Berusaha membuka transaksi baru dengan merubah calon pembeli menjadi pembeli, 5) Responsive Selling, Dua jenis penjualan disini adalah route driving dan retailing. Jenis penjualan seperti ini tidak akan menciptakan penjualan yang terlalu besar meskipun layanan yang baik dan hubungan pelanggan yang menyenangkan dapat menjurus kepada pembelian ulang.

Toko Raffamart merupakan sebuah toko yang menjual berbagai jenis pakaian mulai dari pakaian anak-anak sampai dewasa, seperti gaun, dress, kemeja, atasan, baju tidur, celana, daster, jaket dan jilbab. Dalam proses transaksi penjualan dan pemesanan produk pada toko Raffamart pelanggan harus meluangkan waktu untuk datang langsung ketempat. Pelanggan tidak dapat melakukan pemesanan produk karena keterbatasan sistem yang dimiliki oleh toko Raffamart. Jika dilihat dari segi pemasaran produk hanya mencakup daerah sekitar toko, tidak menyebarkan brosur ataupun media sosial.

Untuk membantu promosi dan pemasaran produk-produk yang ada di toko Raffamart. Website ini gunanya untuk katalog, $e$ commerce, informasi dan lain sebagainya. Ecommerce merupakan kegiatan-kegiatan bisnis yang menyangkut konsumen (consumers), manufaktur (manufactures), services profiders dan pedagang perantara (intermediaries) dengan menggunakan jaringan-jaringan komputer (computer networks) yaitu internet (Husda dan Wangdra, 2016).

Secara umum e-commerce dapat diklasifikasikan menjadi dua jenis, yaitu: 1) Business to Business (B2B), merupakan bentuk jual beli produk atau jasa yang melibatkan dua atau beberapa perusahaan secara elektronik. Umumnya perusahaanperusahaan yang terlibat adalah pemasok, distributor, pabrik, toko dan lainnya, dan 2) Business to Consumer (B2C), adalah bentuk jual beli yang melibatkan perusahaan penjual dan konsumen akhir yang akan dilakukan secara elektronis.

Sistem e-commerce yang dibangun menggunakan macromedia dreamweaver yaitu program aplikasi profesional untuk mengedit HTML secara visual dan mengelola website serta pages. Karena tampil secara visual, program aplikasi macromedia dreamweaver mudah untuk dioperasikan. Program ini menyediakan banyak perangkat yang dapat 
meningkatkan kemampuan user didalam membuat web. Sedangkan untuk coding digunakan PHP (Hipertext Preprocessor), yaitu adalah bahasa pemrograman script server-side yang didesain untuk pengembangan web (Madcoms, 2016). Disebut sebagai bahasa pemrograman server-side karena PHP diproses pada komputer server. Hal ini berbeda dibandingkan dengan bahasa pemrograman client-side seperti javascript yang diproses pada web browser (client). PHP dapat digunakan dengan gratis (free) dan bersifat open source.

\section{METODOLOGI PENELITIAN}

\subsection{Metode Penelitian}

Metode penelitian yang digunakan dalam merancang dan membangun Sistem yang direncanakan adalah Metode Deskriptif. Metode deskriptif adalah metode yang digunakan untuk menganalisis data dengan cara mendeskripsikan atau memberikan gambaran dari data yang telah terkumpul sebagaimana adanya tanpa bermaksud membuat kesimpulan yang berlaku untuk umum atau generalisasi. (Sugiyono, 2013).

\subsection{Metode Pengumpulan Data}

Teknik pengumpulan data yang digunakan untuk merancang dan membangun sistem yang direncanakan adalah: 1)Teknik Wawancara, merupakanPengumpulan data dengan cara tanya jawab secara langsung kepada pihak-pihak yang terkait dalam objek penelitian. Data diperoleh dari sumber secara langsung dilokasi penelitian, seperti data produk, harga produk, jenis produk dan sebagainya, dan 2) Teknik Observasi, merupakan teknik pengumpulan data dengan melakukan pengamatan langsung ke objek yang diteliti. Untuk mendapatkan data yang bersifat nyata dan meyakinkan yang berkaitan dengan permasalahan yang ada. Informasi yang berkaitan adalah proses jalannya sistem penjualan di Toko Raffamart. (Rosa dan Shalahudin, 2016)

\subsection{Metode Pengembangan Sistem}

Model waterfall sering juga disebut model air terjun dibagi beberapa tahapan (Simarmata, 2010) sebagai berikut:

\section{Kebutuhan Sistem}

Permodelan ini diawali dengan mencari kebutuhan dari keseluruhan sistem yang akan diaplikasikan ke dalam bentuk software. Hal ini sangat penting mengingat software harus dapat berinteraksi dengan elemen-elemen lain seperti hardware, database dan sebagainya.

2. Spesifikasi Kebutuhan Perangkat Lunak Merupakan atribut yang diperlukan dalam sistem. Spesifikasi kebutuhan ini sangat penting karena memberikan basic untuk semua pekerjaan pengembangan yang diikuti.

\section{Desain Perangkat Lunak}

Tahap ini dilakukan sebelum melakukan coding. Bertujuan untuk memberikan gambaran apa yang seharusnya dikerjakan dan bagaimana tampilannya.

4. Implementasi Perangkat Lunak 
Dalam tahap ini dilakukan pemrograman. Pembuatan software dipecah menjadi modulmodul kecil yang nantinya akan digabungkan dalam tahap berikutnya. Dilakukan pemeriksaan terhadap modul yang dibuat, apakah sudah memenuhi fungsi yang diinginkan atau belum.

5. Uji Mesin Format Integrasi perangkat lunak

Tahap ini dilakukan penggabungan modulmodul yang sudah dibuat dan dilakukan pengujian ini dilakukan untuk mengetahui apakah software yang dibuat telah sesuai dengan desainnyadan masih terdapat atau tidak.

6. Operasi dan Perawatan

Merupakan tahap terakhir dalam metode waterfall. Software yang sudah jadidan dijalankan serta dilakukan pemeliharaan.

\section{HASIL DAN PEMBAHASAN}

Hasil penelitian merupakan sebuah ecommerce yang digunakan untuk membantu memperluas jangkauan penjualan pada Toko Raffamart yang menjual produk pakaian mulai dari pakaian anak-anak sampai dewasa, seperti gaun, dress, kemeja, atasan, baju tidur, celana, daster, jaket dan jilbab. E-commerce yang dibangun memberikan fitur-fitur yang memberikan kemudahan dalam bertransaksi secara online.

Pengembangan aplikasi ini menggunakan metode Waterfall. Dengan Tahapan kerja dari Kebutuhan Sistem, Spesifikasi Kebutuhan Perangkat Lunak, Desain Perangkat Lunak, Implementasi Perangkat Lunak, Pengujian dan
Pemeliharaan. (Simarmata, 2010).

Pada Tahap Perancangan kegiatan yang dilakukan adalah membuat rancangan proses, rancangan database dan rancangan program yang akan digunakan sebagai pedoman dalam membangun sistem yang direncanakan.

\subsection{Perancangan Sistem}

Perancangan sistem merupakan tahap selanjutnya setelah analis sistem, gambaran dengan jelas tentang apa yang dikerjakan pada analisa sistem, dilanjutkan dengan memikirkan bagaimana membentuk sistem tersebut.

\section{Use Case Diagram}

Use Case mendeskripsikan sebuah interaksi antara satu atau lebih aktor dengan sistem informasi yang akan dibuat. Use Case digunakan untuk mengetahui fungsi apa saja yang ada didalam sebuah sistem informasi dan siapa saja yang berhak menggunakan fungsi-fungsi itu. Use Case Diagram Sistem dapat dilihat pada gambar 1 .

\section{Activity Diagram}

Activity Diagram Sistem terdiri dari 3 aktivitas, yaitu pelanggan, admin dan pimpinan. Ketiga Activity Diagram tersebut dapat dilihat pada gambar 2,3 dan 4 .

\section{Class Diagram \\ Class diagram dibuat agar pembuat} program atau programmer membuat kelas-kelas sesuai rancangan didalam diagram kelas agar antara dokumentasi perancangan dan perangkat lunak sinkron. Classs Diagram dapat dilihat pada gambar 5 


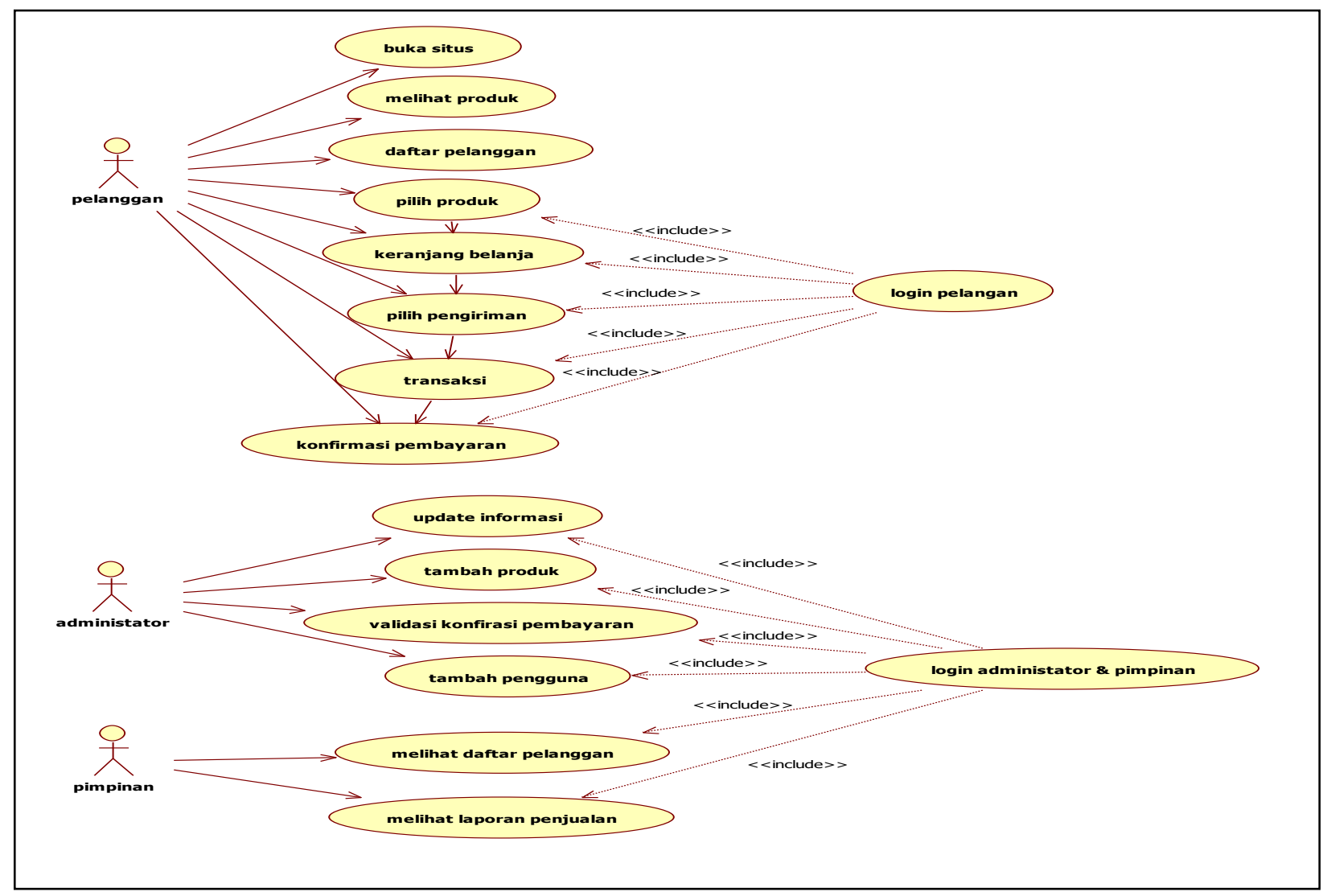

\section{Gambar 1 Use Case Diagram}

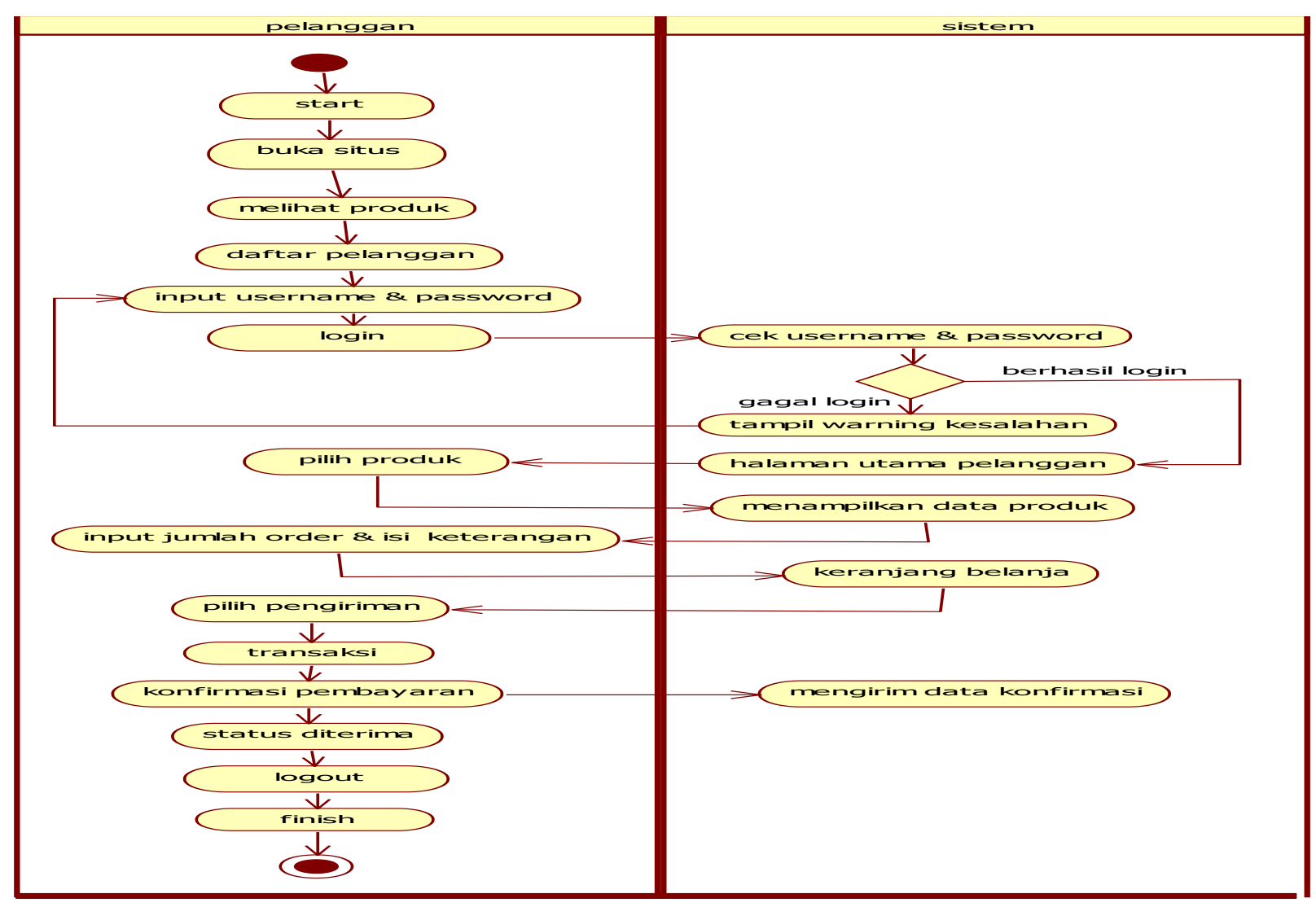

Gambar 2 Activity Pelanggan 


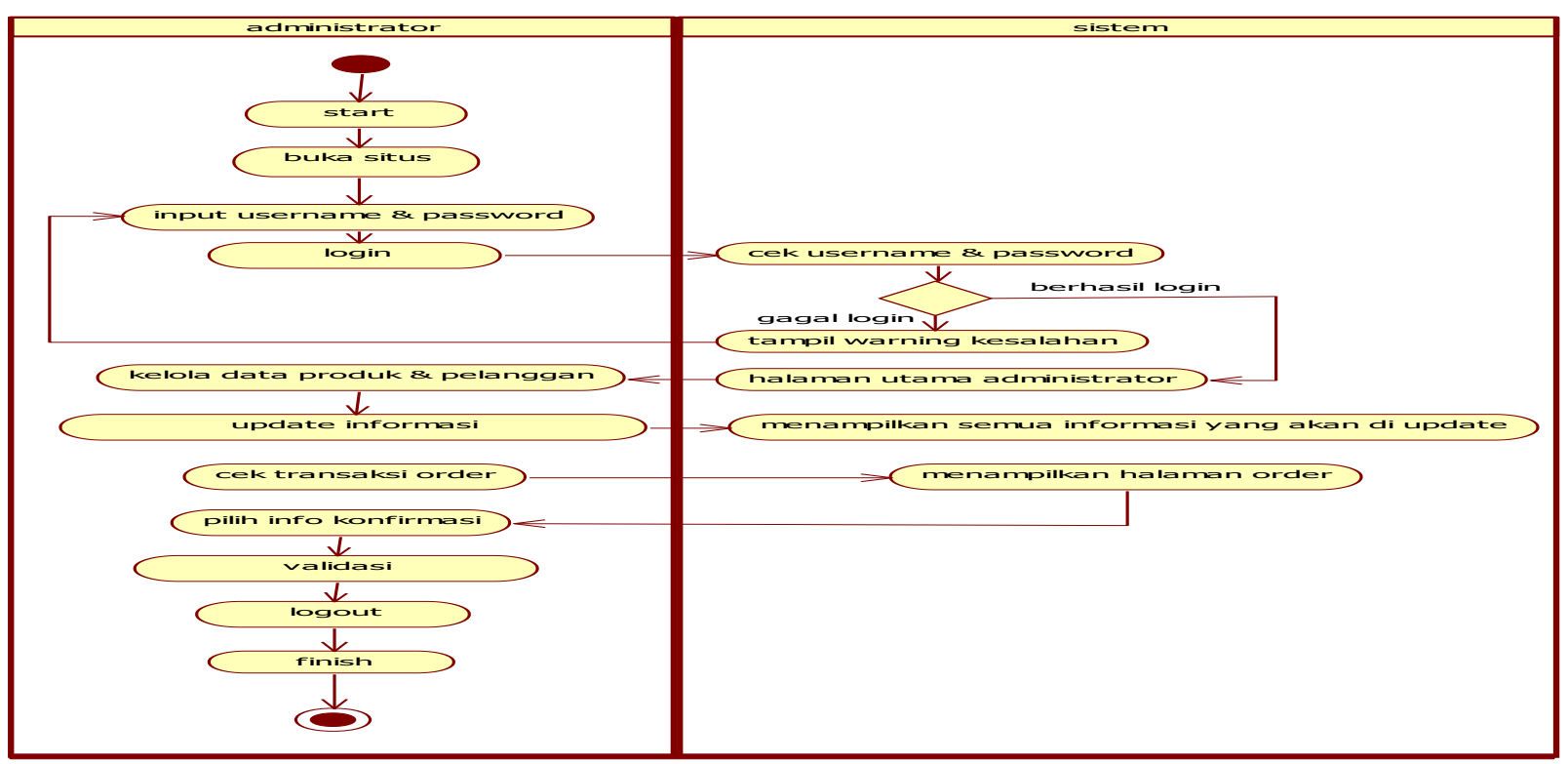

\section{Gambar 3 activity Administrator}

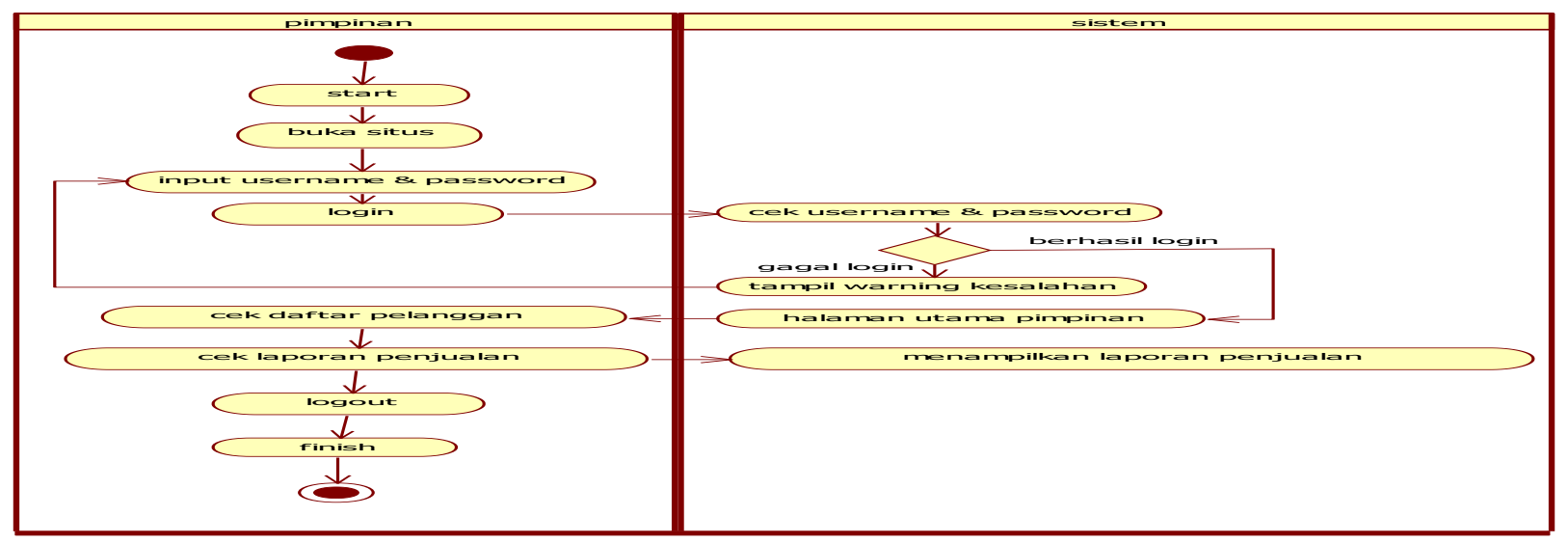

Gambar 4. Activity Pimpinan

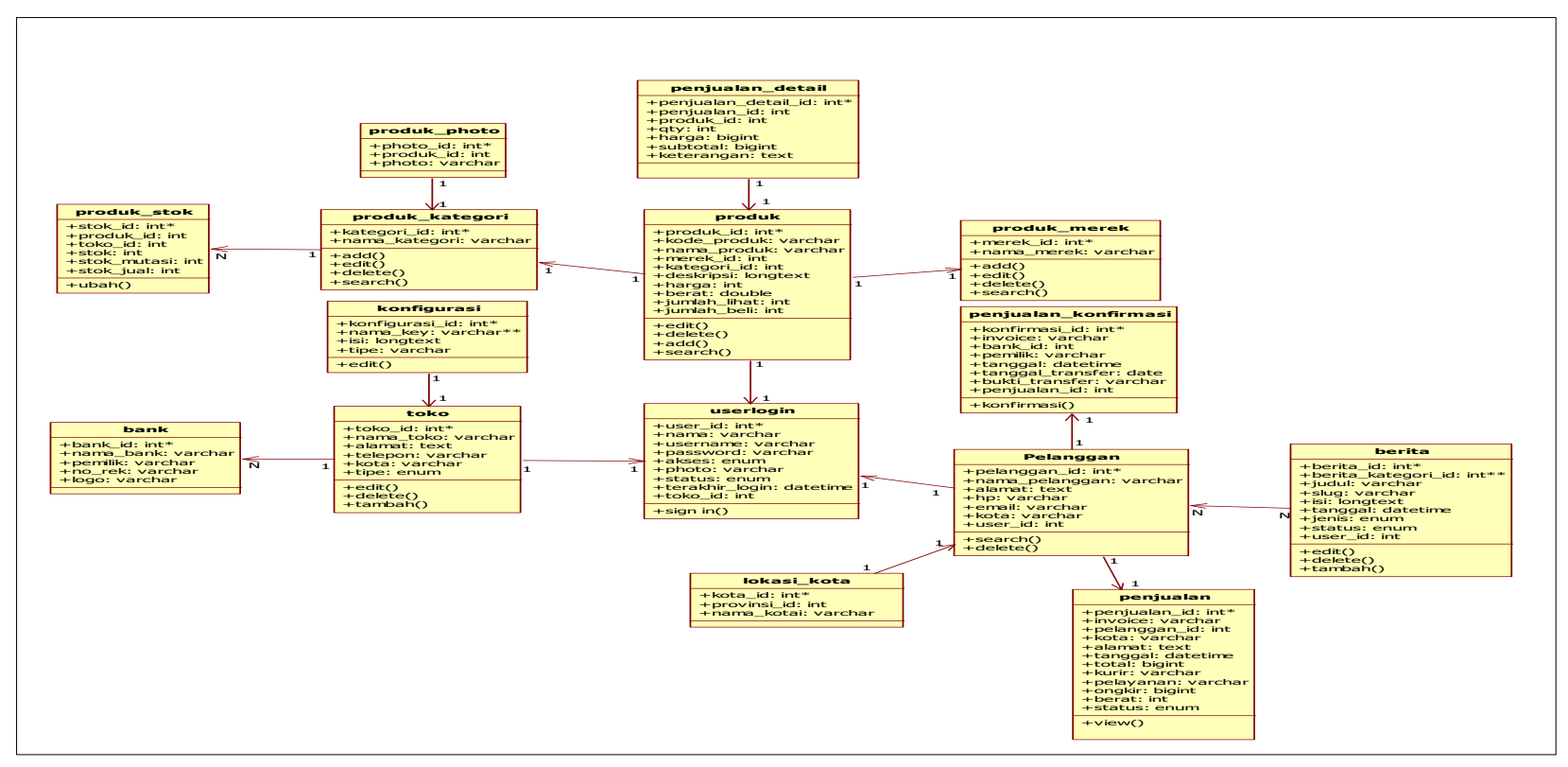

Gambar 5. Class Diagram 


\subsection{Rancangan Basis Data}

Berdasarkan rancangan use case diagram, dan Activity Diagram, maka database dalam penelitian ini adalah sebagai berikut;

Tabel userlogin digunakan untuk pengguna web melakukan login dan mengelola web. Adapun filed yang terdapat pada tabel ini adalah; User_id, Nama, Username, Password, Akses, Photo, Status, Terakhir_login, Toko_id.

Tabel bank digunakan untuk menyediakan jasa pembayaran yang lebih efisien dalam proses pembayaran tagihan belanja online shop. Adapun filed yang terdapat pada tabel ini adalah; Bank_id, Nama_bank, Pemilik, No_rek, Logo.

Tabel berita digunakan untuk menyimpan isi dari menu informasi. Adapun filed yang terdapat pada tabel ini adalah; Berita_id, Berita, kategori_id, Judul, Slug, Isi, Tanggal, Jenis Status, User_id.

Tabel ini digunakan untuk menyimpan data aplikasi perusahaan serta pengaturan tema dan logo web. Adapun filed yang terdapat pada tabel ini adalah; Konfigurasi_id, Nama_key, Isi, Tipe.

Tabel lokasi_kota digunakan untuk menyimpan daftar nama kota yang ada didalam provinsi, tujuannya adalah untuk menyimpan besarnya biaya pengiriman produk dari toko raffamart berada menuju kota tujuan pengiriman. Adapun filed yang terdapat pada tabel ini adalah; Kota_id, Provinsi_id, Nama_kota

Tabel Pelanggan digunakan untuk menyimpan data pelanggan yang sudah pernah mendaftar menjadi member. Adapun filed yang terdapat pada tabel ini adalah; Pelanggan_id, Nama_pelanggan, Alamat, Hp, Email, KotaUser_id

Tabel penjualan digunakan untuk menyimpan data penjualan produk. Adapun filed yang terdapat pada tabel ini adalah; Penjualan_id, Invoice, Pelanggan_id, Kota, Alamat, Tanggal, Total, Kurir, Pelayanan, Ongkir, Berat, status

Tabel penjualan_detail digunakan untuk menyimpan produk yang sudah dipesan. Adapun filed yang terdapat pada tabel ini adalah; Penjualan_detail_id, Penjualan_id, Produk_id, Qty, Harga, Subtotal, Keterangan.

Tabel penjualan_konfirmasi digunakan untuk menyimpan data penjualan yang telah dikonfirmasi oleh pelanggan. Adapun filed yang terdapat pada tabel ini adalah; Konfirmasi_id, Invoice, Bank_id, Pemilik, Tanggal, Tanggal_transfer, Bukti_transfer, Penjualan_id.

Tabel Produk digunakan untuk menyimpan data produk. Setiap data dikelompokkan berdasarkan data kategori dan merek. Adapun filed yang terdapat pada tabel ini adalah; Produk_id, Kode_produk, Nama_produk, Merek_id, Kategori_id, Harga, Berat, Jumlah_lihat, Jumlah_beli.

Tabel produk_kategori digunakan untuk menyimpan data kategori, fungsinya untuk mengelompokan data produk. Kategori dipakai untuk menu. Adapun filed yang terdapat pada tabel ini adalah; Kategori_id, Nama_kategori.

Tabel produk_merek digunakan untuk menyimpan data merek, fungsinya untuk mengelompokan data produk. Merek dipakai 
untuk menu. Adapun filed yang terdapat pada tabel ini adalah; Merek_id, Nama_merek.

Tabel produk_photo digunakan untuk menyimpan gambar produk. Adapun filed yang terdapat pada tabel ini adalah; Photo_id, Produk_id, Photo.

Tabel produk_stok digunakan untuk menyimpan data stok produk. Adapun filed yang terdapat pada tabel ini adalah; Stok_id, Produk_id, Toko_id, Stok, Stok_mutasi, Stok_jual.

Tabel took digunakan untuk menyimpan data toko. Adapun filed yang terdapat pada tabel ini adalah; Toko_id, Nama_toko, Alamat, Telepon, Kota, Tipe.

\subsection{Rancangan Interface}

Rancangan Interface (Antar muka), merupakan gambaran tentang hubungan antara Sistem dan Pengguna. E-commerce yang akan dibangun.

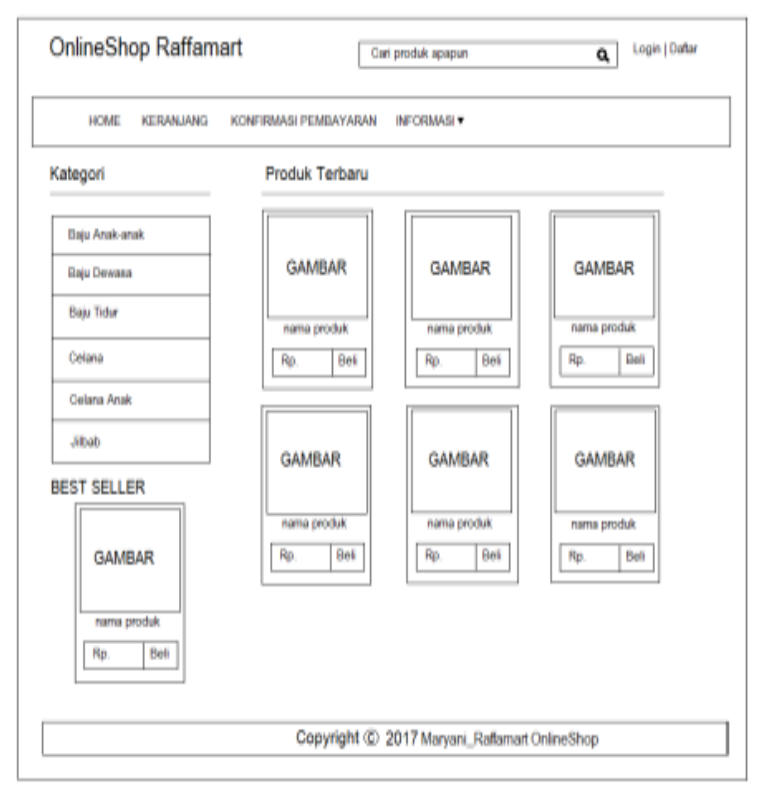

Gambar 6. Rancangan Halaman Utama

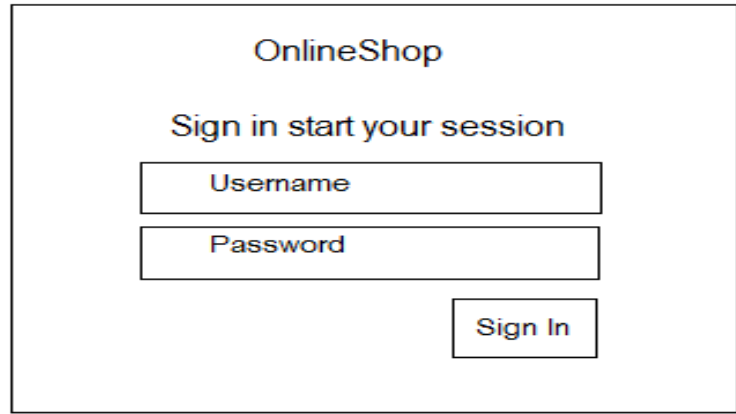

Gambar 8. Rancangan Halaman Login

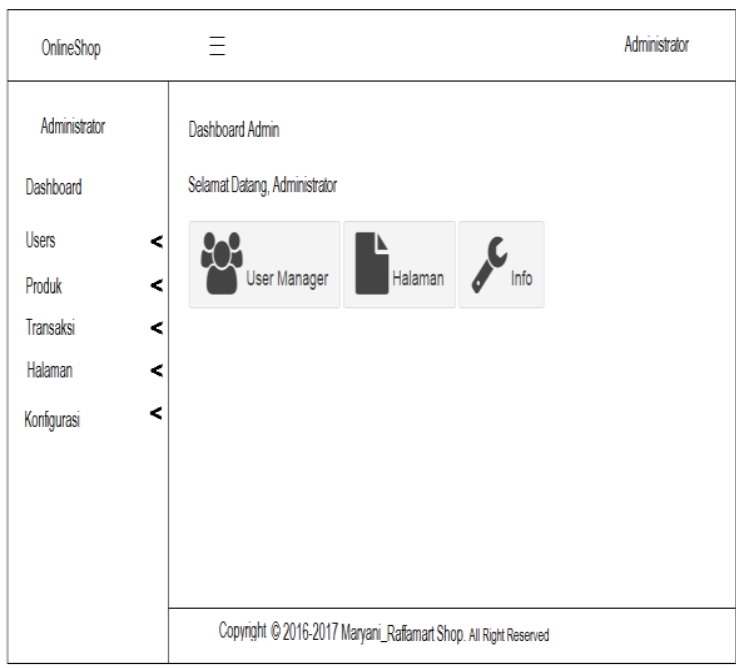

Gambar 8. Rancangan Halaman Utama

Administrtor

\subsection{Implementasi Rancangan e-commerce}

Berdasarkan rancangan Sistem, Rancangan Basis Data dan Rancangan Interface yang sudah dilakukan sebelumnya, proses selanjutnya adalah mengimplemetasikan rancangan tersebut dengan melakukan pengkodean (coding) untuk memperoleh $e$ commerce yang diinginkan sesuai rancangan yang telah ada. Berikut ini adalah hasil coding yang dilakukan sehingga menghasilkan ecommerce Toko Raffamart Palembang menggunakan Macromedia Dreamwaver. 


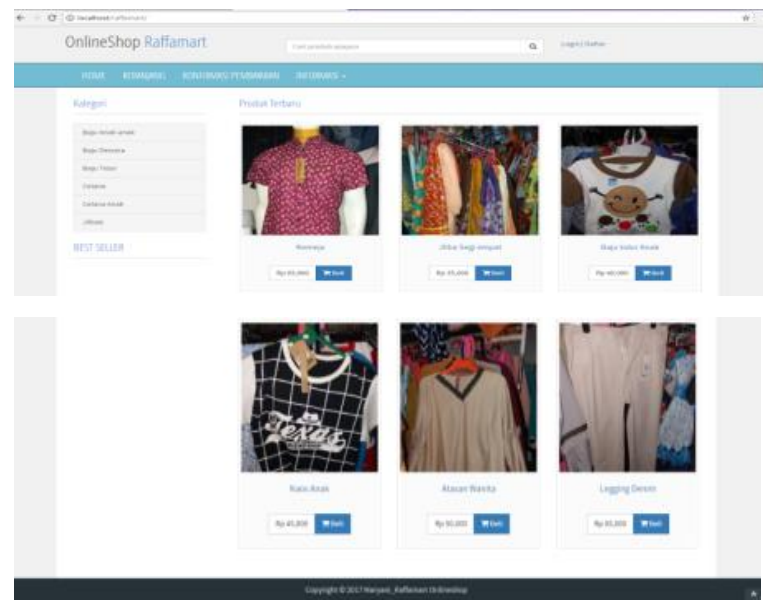

Gambar 9 Halaman Utama

Halaman utama menampilkan halaman awal yang diperuntukkan bagi pelanggan atau pengunjung untuk mengetahui produk yang tersedia, seperti yang dapat dilihat pada gambar 9.

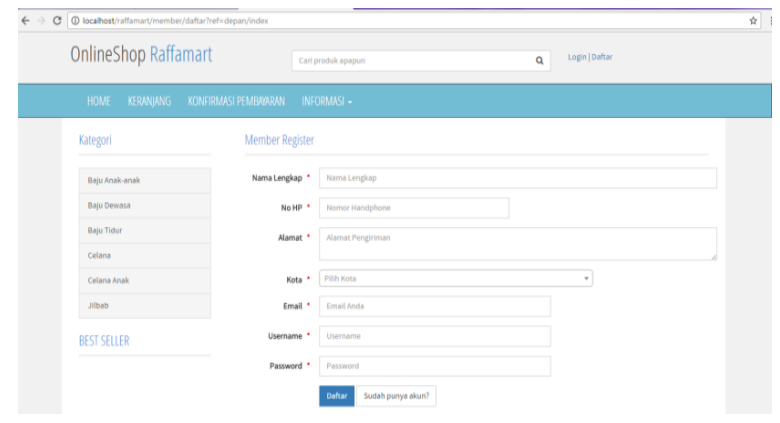

\section{Gambar 10 Halaman Member Register}

Untuk melakukan transaksi, pengunjung harus melakukan registrasi terlebih dahulu dengan mengisi data dihalaman registrasi. Setelah melakukan registrasi, maka pengunjung akan mendapatkan username dan password untuk melanjutkan transaksi dengan melakukan login seperti terlihat pada gambar 10 dan 11 .

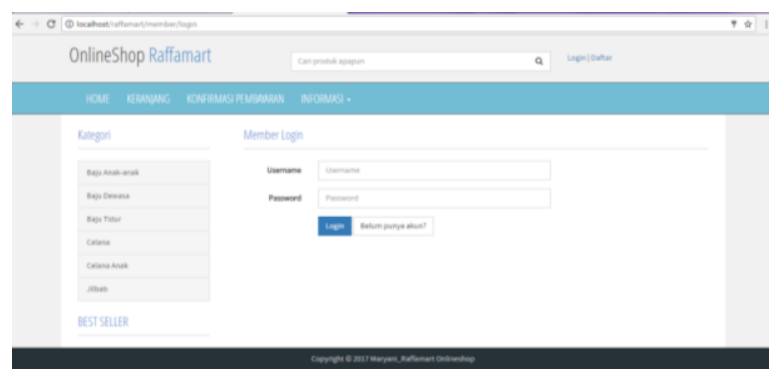

Gambar 11 Halaman Member Login
Untuk membeli barang yang diinginkan, customer dapat memilih produk yang diinginkan serta melihat detil produk yang mereka pilh. Seperti terlihat pada gambar 12

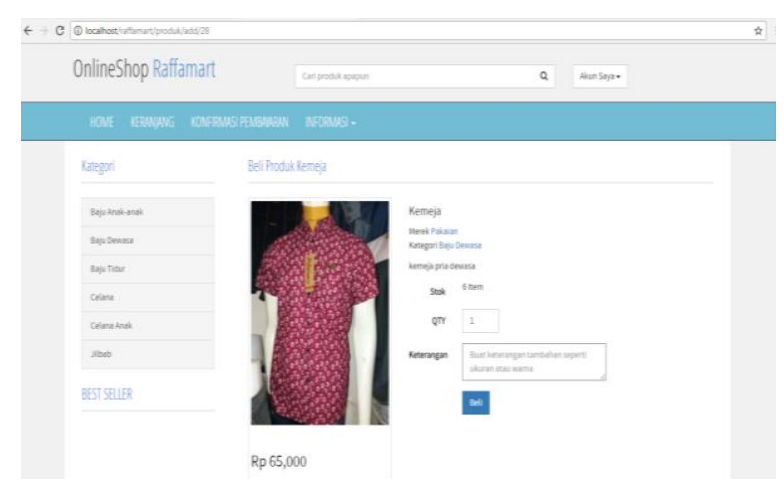

Gambar 12 Halaman Beli Produk

Barang yang ingin dibeli dimasukkan ke keranjang belanja untuk kemudian dapat dihitung total pembelian yang dilakukan oleh customer. Halaman untuk menu ini dapat dilihat pada gambar 13 dan 14 .

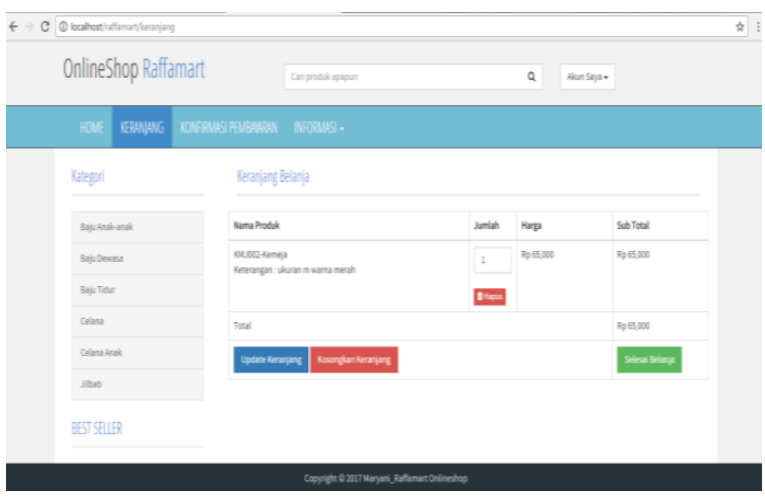

Gambar 13 Halaman Keranjang Belanja

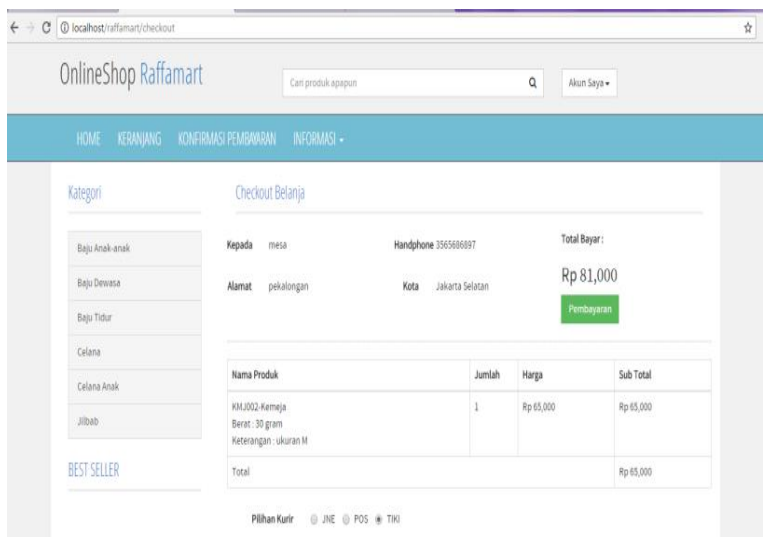

Gambar 13 Halaman Total Belanja 
Customer dapat melakukan cetak invoice untuk mengetahui total biaya yang harus mereka bayarkan termasuk biaya pengiriman yang dipilih. Pada halaman ini juga diinformasikan bank yang dapat digunakan untuk melakukan transfer. Seperti terlihat pada gambar 14.

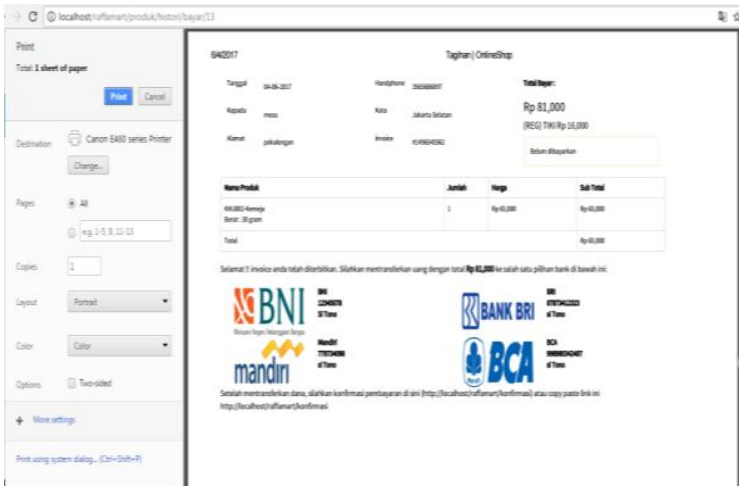

\section{Gambar 14 Halaman Cetak Invoice}

Menu Administrator akan tampil jika Admin melakukan Login pada sistem. Menu admin digunakan untuk mengelola e-commerce yang telah di bangun. Setelah masuk kehalaman Admin, maka admin dapat mengelola sistem $e$ commerce tersebut, anatara lain; mengelola data produk, Mengelola data transaksi, mengelola kofigurasi sistem serta laporan yang akan diberikan kepada pimpinan.

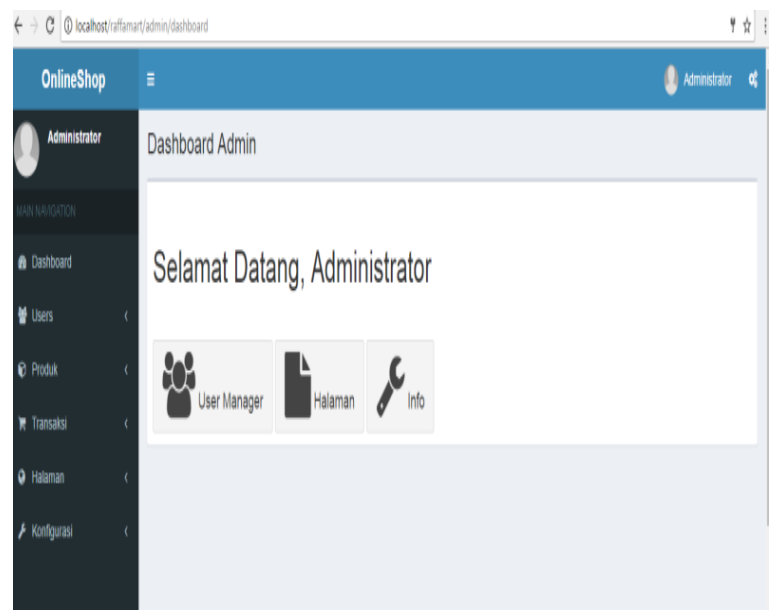

Gambar 15. Halaman Administrator

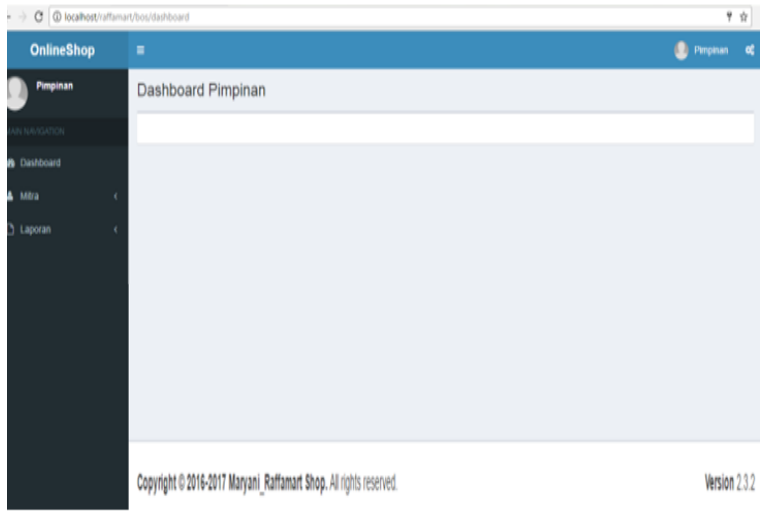

Gambar 16. Halaman Administrator

Menu Pimpinan merupakan halaman yang dapat diakses oleh Pimpinan untuk melihat Laporan transaksi yang dilakukan melalui Sistem e-commerce yang sebelumnya telah dikelola oleh staff Admin. Pada halaman pimpinan ini terdapat menu Mitra yang memuat data pelanggan dan outlet yang ada dan laporanlaporan yang terkait dengan transaksi penjualan yang dilakukan.

\section{SIMPULAN}

Penelitian ini menghasilkan E-commerce ti pada toko Raffamart Palembang yang dapat mendukung proses bisnis yang berkaitan dengan penjualan, pembelian serta transaksi. Dengan adanya Sistem e-commerce yang dibangun Konsumen dapat memesan produk pada toko raffamart ini dimana saja yang terhubung dengan jaringan internet, konsumen hanya perlu mendaftar, melakukan login, memilih produk dan melakukan pemesanan. Selain itu Dengan adanya basis data untuk penyimpanan data, maka informasi dan data dapat dikelola dengan baik serta laporan kepimpinan yang lebih efektif dan mudah berdasarkan periode tertentu. 


\section{DAFTAR PUSTAKA}

Husda, Nur Elfi \& Yvonne Wangra. 2016. Pengantar Teknologi informasi. Jakarta: Baduose Media.

Madcoms. 2016. Sukses Membangun Toko Online dengan PHP \& MySQL. Yogyakarta : Andi.

Rosa \& Shalahuddin. 2015. Rekayasa Perangkat Lunak Terstruktur dan Berorientasi Objek. Bandung : Informatika Bandung.

Simarmata, Janner. 2010. Rekayasa Perangkat Lunak. Yogyakarta : Andi.

Swastha, Basu. 2015. Manajemen Penjualan Edisi 3. Yogyakarta : BPFE Yogyakarta.

Sugiyono. 2013. Metode Penelitian Pendidikan Pendekatan Kuantitatif, Kualitatif, dan $R \& D$. Bandung: Alfabeta 